\title{
Fibrogenic effect of wollastonite compared with asbestos dust and dusts containing quartz
}

M Cambelová, A Juck

\begin{abstract}
The distribution of length and diameter and the aspect ratio of crocidolite asbestos, a mineral substitute for asbestos (wollastonite), a manmade mineral fibre (glass wool), and synthetic fibres (polypropylene and polyacrylonitrite) were determined by light microscopy with phase contrast and, for crocidolite, also with transmission electron microscopy. The synthetic organic fibres and manmade mineral fibre used were of a size exceeding that considered respirable. Respirable materials were given to rats by the intratracheal method and after exposure for a standard time interval the main indices of fibrogenic effects-the total hydroxyproline content, the wet weight of the lung, and the total lipid content in the lung-were estimated. For wollastonite there was a significant increase in these variables in comparison with the controls. The fibrogenicity was considerably less than that of crocidolite and quartz.
\end{abstract}

(Occup Environ Med 1994;51:343-346)

New types of fibrous materials, used as substitutes for asbestos, cause serious hygienic problems ${ }^{1}$ and are classified as proved carcinogens. ${ }^{2}$

In some cases manmade mineral fibres are considered to be potential carcinogens. ${ }^{3}$ So far there is only limited information about the biological activity of these new materials. ${ }^{4}$

Recent results confirmed that for carcinogenic effects the length, diameter, and their mutual ratio (aspect ratio) were decisive ${ }^{5}$ and they are the subject of intensive research and discussion. ${ }^{67}$

The detailed study of lung cancer and mesothelioma in cases in which the action of asbestos was proved, showed that asbestosis as a specific form of pneumoconiosis probably precedes the development of cancer. ${ }^{89}$ The different aggressiveness of various types of asbestos is emphasised. The carcinogenicity of chrysotile remains questionable, whereas amphibole asbestos, mainly crocidolite, is accepted as a carcinogen. ${ }^{10}$

Currently, wollastonite, a mineral asbestos substitute, attracts considerable attention. It has membranolytic effects on erythrocytes and in in vitro experiments it caused morphological and functional changes in lung macrophages. ${ }^{4}$
We decided, therefore, to determine its fibrogenicity in vivo.

\section{Materials and methods}

MORPHOMETRIC ANALYSIS

This study examined the morphometric variables of asbestos (crocidolite), of a manmade mineral fibre (glass wool), of synthetic organic fibres (polypropylene, polyacrylonitrile), and of two sources of wollastonite, a recent mineral substitute for asbestos. ${ }^{11}$

The length, diameter, and aspect ratio of fibres were determined by light microscopy with phase contrast as previously described ${ }^{12}$; crocidolite was also examined by transmission electron microscopy.

Microphotographic recordings of the individual variables of fibre size and distribution were analysed. For all variables, the average, geometric mean, and SD were calculated.

\section{ANIMALS AND CONDITIONS OF EXPOSURE}

The samples of fibres that could be given to the experimental animals (specific pathogen free male Wistar rats, about $300 \mathrm{~g}$ body weight) were obtained by. mechanical treatment (crushing, sedimentation, etc).

In the fibrogenicity test ${ }^{13}$ the samples of fibrous dusts were given intratracheally during mild ether anaesthesia. For comparison highly fibrogenic standard quartz and low fibrogenic mineral dust of magnesite of mine origin were given. Particles of these two samples were of respirable size (diameter $<5 \mu \mathrm{m}$ ).

In our experiment wollastonite fibres were given and their effects were compared with the action of crocidolite, quartz, mineral mine dust, and controls.

As the synthetic organic fibres were not respirable they were not expected to be fibrogenic.

The number of fibres as well as nonfibrous particles in the samples studied varied depending on particle size. Dose specification by the number of particles would be imprecise because of their different sizes. The gravimetric dose used $(25 \mathrm{mg}$ of a sample in $1 \mathrm{ml}$ of physiological saline) always contained many particles (about $3 \times 10^{9}$ particles/ sample).

Each group contained about 18 animals. Exposure lasted three months. The animals were then killed and the lungs removed for the determination of basic variables of fibrogenicity.

The total content of hydroxyproline in the lung was determined as the main indicator of 
fibrogenicity, and the wet weight of the lung and total content of lipid in the lung were found by standard methods. ${ }^{14}$

\section{Results}

With the exception of two samples of chemical synthetic fibres (polypropylene, polyacrylonitrile) and the glass fibre (Supelco) other samples tested were respirable.

Table 1 summarises mean dimensions of respirable mineral fibres, and table 2 nonrespirable synthetic organic fibres. Biological

Table 1 Metric variables of mineral fibres

\begin{tabular}{lrlc}
\hline & $\begin{array}{l}\text { Length } \\
(\mu \mathrm{m})\end{array}$ & $\begin{array}{l}\text { Diameter } \\
(\mu \mathrm{m})\end{array}$ & $A R$ \\
\hline Crocidolite: & & & \\
$\quad$ Average & 4.42 & 0.32 & 16.03 \\
Geometric mean & 3.93 & 0.29 & 13.48 \\
SD & 2.43 & 0.13 & 10.31 \\
W-Ghina: & & & \\
$\quad$ Average & 12.91 & 1.57 & 11.88 \\
Geometric mean & 11.57 & 1.34 & 9.17 \\
SD & 7.38 & 0.92 & 12.44 \\
W-Nyad: & & & \\
Average & 10.08 & 1.39 & 9.6 \\
Geometric mean & 9.22 & 1.21 & 7.91 \\
SD & 4.59 & 0.72 & 6.76 \\
\hline AR & & &
\end{tabular}

$\mathrm{AR}=$ aspect ratio $\mathrm{W}=$ wollastonite.

Table 2 Dimensions of synthetic organic fibres

\begin{tabular}{|c|c|c|c|}
\hline & $\begin{array}{l}\text { Length } \\
(\mu \mathrm{m})\end{array}$ & $\begin{array}{l}\text { Diameter } \\
(\mu m)\end{array}$ & $A R$ \\
\hline \multicolumn{4}{|l|}{ Glass fibre: } \\
\hline $\begin{array}{l}\text { Average } \\
\text { Geometric mean } \\
\text { SD }\end{array}$ & $\begin{array}{l}51 \cdot 48 \\
45 \cdot 15 \\
28 \cdot 15\end{array}$ & $\begin{array}{l}8 \cdot 31 \\
8 \cdot 25 \\
0 \cdot 98\end{array}$ & $\begin{array}{l}6 \cdot 15 \\
5 \cdot 42 \\
3 \cdot 3\end{array}$ \\
\hline \multicolumn{4}{|l|}{ Polyacrylonitrile: } \\
\hline $\begin{array}{l}\text { Average } \\
\text { Geometric mean } \\
\text { SD }\end{array}$ & $\begin{array}{l}299 \cdot 5 \\
227 \cdot 4 \\
206 \cdot 3\end{array}$ & $\begin{array}{l}32 \cdot 58 \\
31 \cdot 64 \\
8 \cdot 87\end{array}$ & $\begin{array}{l}9 \cdot 2 \\
7 \cdot 19 \\
5 \cdot 91\end{array}$ \\
\hline \multicolumn{4}{|l|}{ Polypropylene: } \\
\hline $\begin{array}{l}\text { Average } \\
\text { Geometric mean } \\
\text { SD }\end{array}$ & $\begin{array}{l}295 \cdot 1 \\
253 \cdot 8 \\
155 \cdot 5\end{array}$ & $\begin{array}{l}37 \cdot 76 \\
34 \cdot 37 \\
17 \cdot 69\end{array}$ & $\begin{array}{l}9 \cdot 22 \\
7 \cdot 38 \\
6 \cdot 28\end{array}$ \\
\hline
\end{tabular}

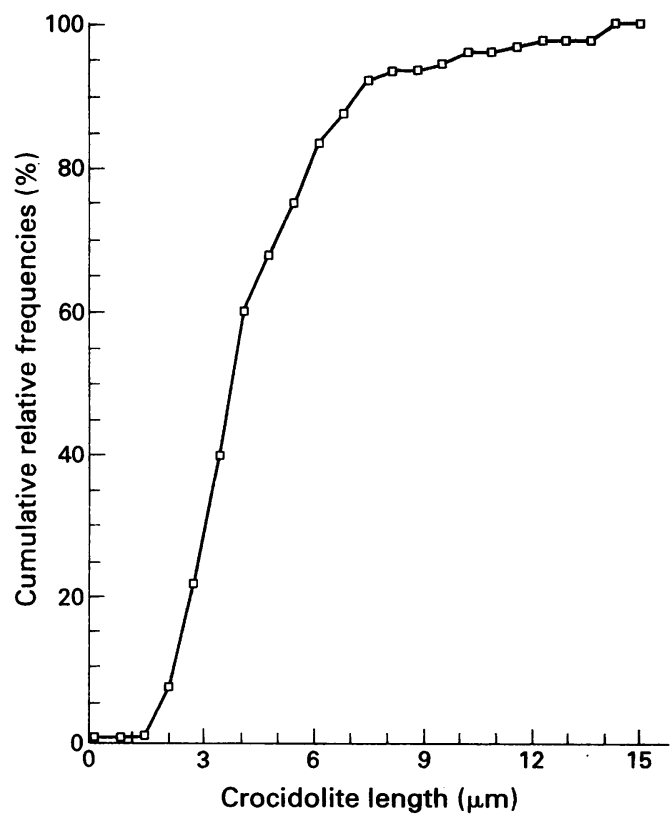

Figure 1 Cumulative distribution curve of length of crocidolite fibres. reactivity of mineral fibres is dependent on fibre dimensions. Only fibres $<3.5 \mu \mathrm{m}$ in diameter reach the alveolar spaces. Fibre

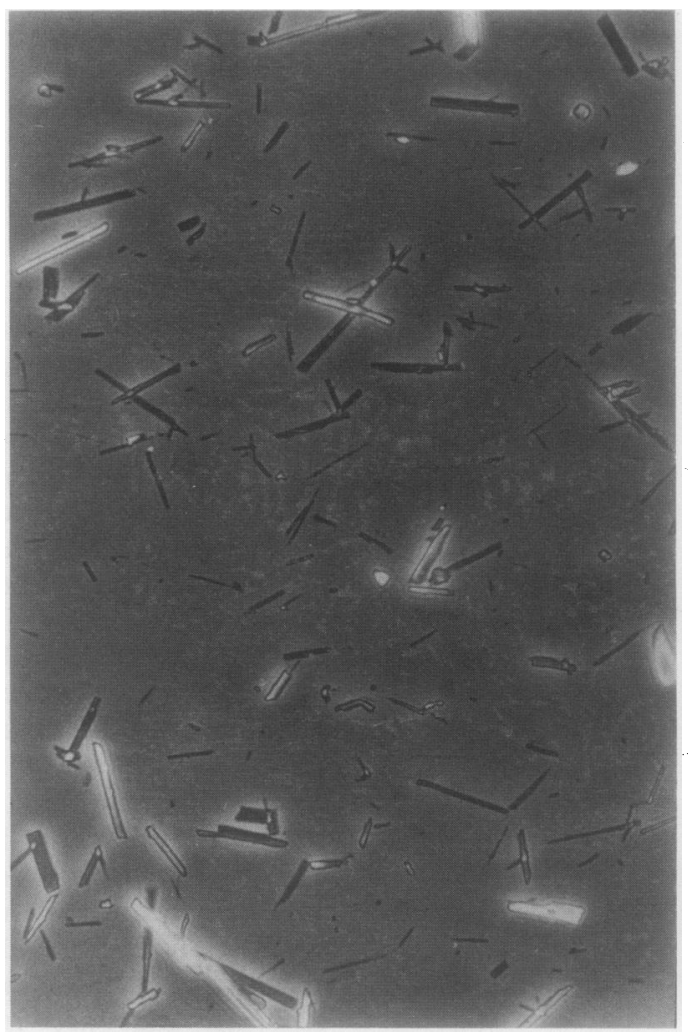

Figure 2 Microphotograph of wollastonite (China) fibres. Light microscopy with phase contrast, originally $\times 1070$.

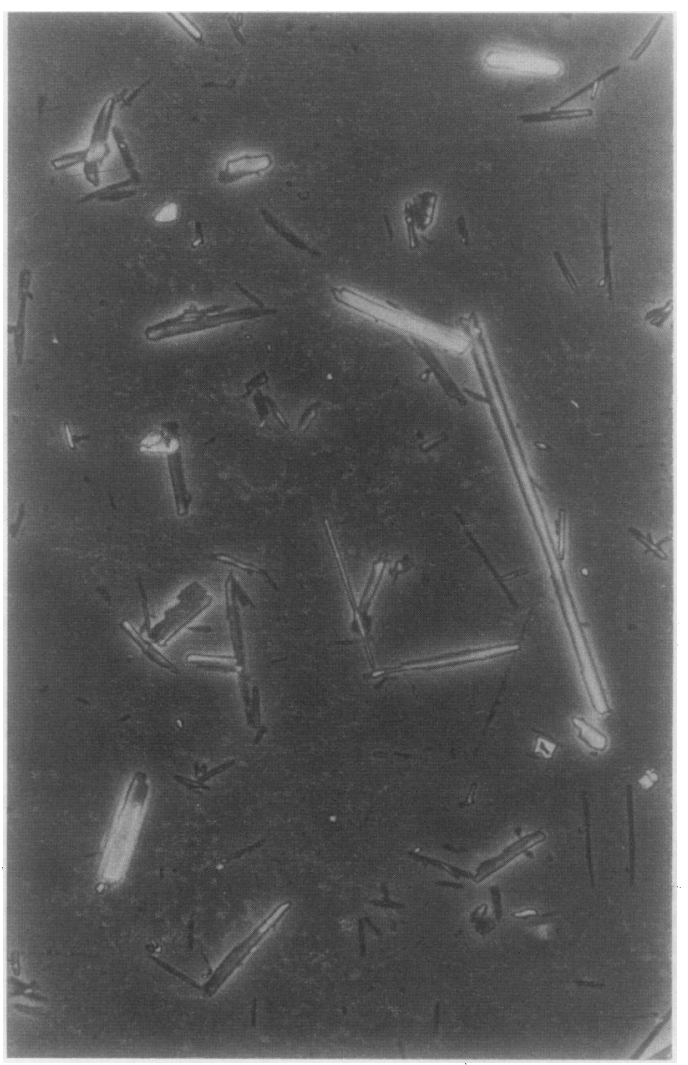

Figure 3 Microphotograph of wollastonite (Nyad) fibres. Light microscopy with phase contrast. Originally $\times 1070$ 
length influences the deposition, clearance, and translocation in the lungs.

Recent studies have shifted the range of fibre dimensions to $8 \mu \mathrm{m}$ in length and $0.25 \mu \mathrm{m}$ in diameter for maximal biological reactivity. ${ }^{15}$ From this point of view biological activity of wollastonite can be expected to be greatest. Crocidolite used in Slovakia has a mean length of only $4.42 \mu \mathrm{m}$ and only $10 \%$ of fibres are longer than $8 \mu \mathrm{m}$ (fig 1). Figures 2,3 , and 4 are microphotographs of the mineral fibres used in our experiment.

Figures 5, 6, and 7 show that the content of hydroxyproline, the main indicator of fibrogenicity, was increased significantly by crocidolite, and (although less pronounced) by wollasonite and mineral dust from the magnesite mine. Similar results were found for values of wet weight of the lung. Total lipid content in the lung was similar for crocidolite and wollastonite but lipid content was not a determining factor for fibrogenicity in this short term study.

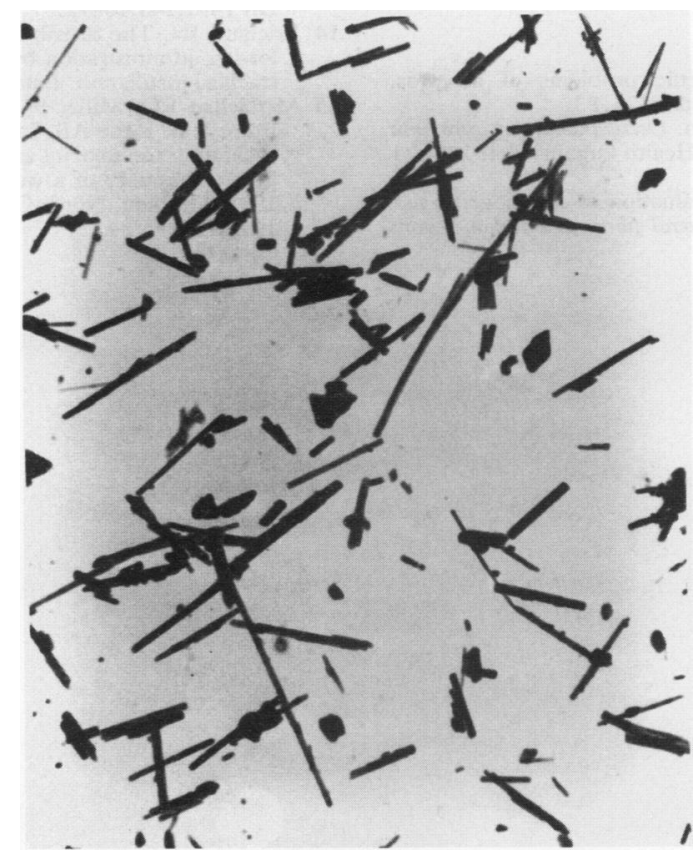

Figure 4 Microphotograph of crocidolite fibres. Transmission electron microscopy. Originally $\times 8000$.

Figure 5 Comparison of hydroxyproline content in rat lungs after exposure to quartz, mine dust (M mine), asbestos (crocidolite), and wollastonite $(W)$ $\star_{p}<0.05 ; * *_{p}<0.01 ;$ ${ }_{p}<0.05 ; *_{* *}^{* *}<0.01 ;$
$x_{p}<0.001$ v control (C).

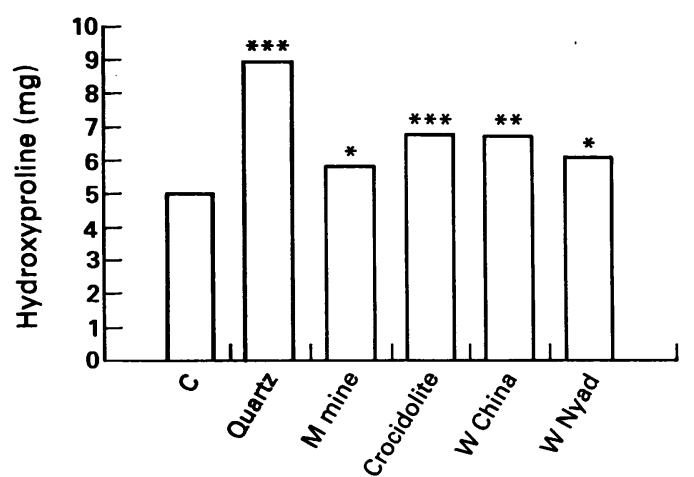

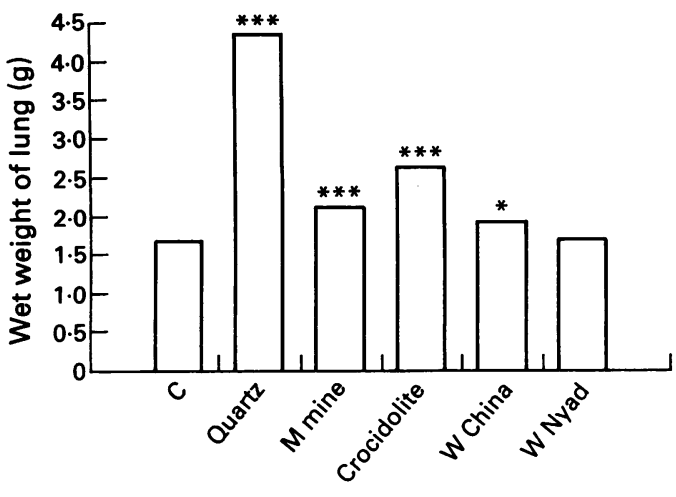

Figure 6 Comparison of wet weight of rat lungs after exposure to quartz, mine dust (M mine), asbestos (crocidolite), and wollastonite (W). $\star_{p}<0.05 ; \star \star \star p<0.001$ v control $(C)$.

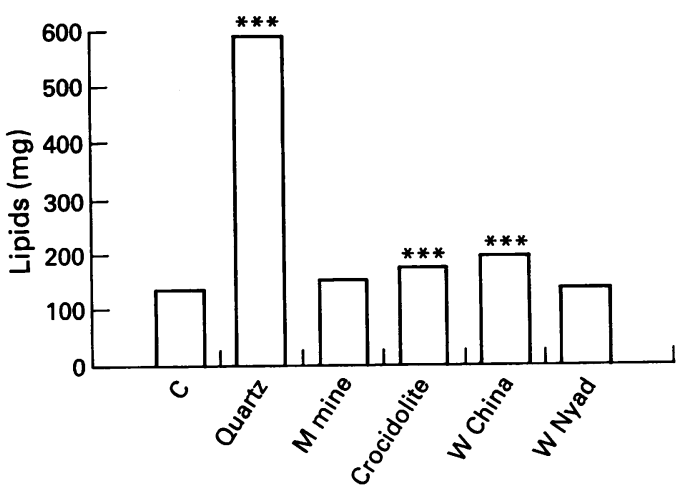

Figure 7 Comparison of lipid content in rat lungs after exposure to quartz, mine dust (M mine), asbestos (crocidolite), and wollastonite (W). $\star * x p<0.001 v$ control (c).

\section{Discussion}

The advantage, from the point of view of hygiene, of the synthetic organic fibres as asbestos substitutes is their size, which excludes respirability. This is, however, achieved at the expense of their technological properties. Other substitutes, including mineral fibres, are therefore looked for.

One of the most promising substitutes seems to be wollastonite. Added to cement building materials it offers efficient refractory protection.

The studies of the biological effects of wollastonite have until now been focused on its experimentally determined cytotoxicity and on the lung damage that was found in epidemiological studies. The aim of our work has been to contribute to the evaluation of its fibrogenicity under experimental conditions.

Data on the fibrogenicity of the two types of wollastonite in experimental conditions are important. The sample with higher respirability (table 1 ) is also more fibrogenic. Its fibrogenicity is lower than that of quartz but comparable with that of crocidolite (figs 4 and 5).

Crocidolite is expected to be considerably more fibrogenic. In assessing its fibrogenic properties it is nevertheless necessary to take into consideration the fact that crocidolite fibres were relatively short (mean $4.4 \mu \mathrm{m}$ ). 
The results of our experiment do not elucidate possible carcinogenic effects of the samples given. According to $\mathrm{McClellan}$ et $\mathrm{al}^{15}$ short term assays can gauge the fibrogenic potential of fibres but cannot accurately assess their carcinogenic potential. The similar increase in the indices of fibrogenicity found in crocidolite and wollastonite does not exclude the carcinogenicity of crocidolite.

Wollastonite as a natural mineral asbestos substitute has good technological features, and is therefore expected to be widely used. It has, nevertheless, turned out to be not wholly inert, a fact that will necessitate further research focused on its biological effects.

Synthetic organic fibres used in Slovakia are not of respirable size. They are therefore not supposed to present a health risk from the point of view of their fibrogenicity.

Mineral substitutes for asbestos (wollastonite) have fibre dimensions that are associated with fibre respirability, fibrogenicity, and possible carcinogenicity. These fibres will be used only as asbestos substitutes in special cases in which they are not expected to cause any serious health hazards.

1 Bencko V, Liška D. Hygienic problems of asbestos. Ceskoslovenská hygiena 1983;28:474-83.

2 Office of Occupational Health. Occupational exposure limit for asbestos. Geneva: World Health Organisation 1989 (1 WHO/OCH/89)

3 IARC Monographs on the evaluation of carcinogenic risk to humans. Man made mineral fibres and radon. Lyon:
IARC, 1988;43:87-152.

4 Dunnigan J. Biological activity of selected asbestos substitutes. $A$ review of recently published data. Scherbrooke, Canada: A reviewo of recently published data. Scherbrooke, Canada: The Asb.

5 Davis JMG. Data from experimental studies on the mechanisms of fibre related disease. Proceedings of the 7th ALA/NIOH international colloguium on dust measurement techriques and strategy. Budapest, Hungary: Nationa Institute of Occupational Health, 1991, 12-23.

6 Rogers AJ, Leigh J, Berry G, Ferguson DA, Mulder HB, Ackad M. Relationship between lung asbestos fiber type concentration and relative risk of mesothelioma. Cancer 1991;67:1912-20.

7 Adamson IYR Letourneau HI Bowden DH Comparison of alveolar and interstitial macrophages in fibroblast stimulation after silica and long or short fibroblast stimulation after silica

8 Navrátil M. Asbestos medical research in Czechoslovakia. Sourcesbook on asbestos diseases, asbestos medical aspect. Souncesbook on asbestos diseases, asbestos
New York: Garlands, 1989;4:395-442.

9 Mossman BT, Bienon J, Corn M, Seaton A, Gee JBL. Asbestos: scientific developments and implication for public policy. Science 1990;247:294-301.

10 Dunnigan J. A scientific update on asbestos and health Meeting of the Intermational growp on the safe use of asbestos. Geneva: International Labour Organisation 1988, 1-65.

11 Pailes WH, Judy DJ, Resnick H, Castranova V. Relative effects of asbestos and wollastonite on alveolar macrophages. I Toxicol Environ Health 1984;14: 497-510.

12 Asbestos International Association. Reference method for the determination of airborne asbestos fibre concentrathe determination of airborne asbestos fibre concentrations at the workplace by light microscopy. London: AIA, 1982:1-40. (Health and Safety

13 William NR, Travis WD, Brody AR. Cellular and molecular basis of the asbestos related diseases. Am Rev Respir Dis 1991;143:408-22.

14 Prichard JN. The distribution of dust in the rat lung following administration by inhalation and by single intratracheal instillation. Environ Res 1985;36:268-97.

15 McClellan RO, Miller FJ, Hesterberg TW, Warheit DB, Bunn WB, Kane AB, Lippman M, et al. Approaches to eraluating the toricity and carcinogenicity of man-made fibres: 1991, Durham, North Carolina. Regul Toxicol Pharmacol 1992;16:321-64. 